\title{
ARV-based HIV prevention for women: State of the science and considerations for implementation in Zimbabwe. Report from a provider workshop
}

Population Council

Follow this and additional works at: https://knowledgecommons.popcouncil.org/departments_sbsr-hiv

Part of the Demography, Population, and Ecology Commons, Family, Life Course, and Society Commons, and the International Public Health Commons How does access to this work benefit you? Let us know!

\section{Recommended Citation}

Population Council. 2015. "ARV-based HIV prevention for women: State of the science and considerations for implementation in Zimbabwe. Report from a provider workshop." New York: Population Council. 


\section{ARV-BASED HIV PREVENTION FOR WOMEN:}

STATE OF THE SCIENCE AND CONSIDERATIONS FOR IMPLEMENTATION IN ZIMBABWE

REPORT FROM A PROVIDER WORKSHOP 27-28 MAY 2014 
This activity was made possible by the generous support of the American people through the United States Agency for International Development (USAID). The contents are the sole responsibility of the Population Council and do not necessarily reflect the views of USAID or the United States Government.

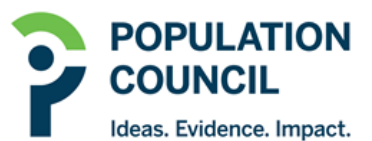

The Population Council confronts critical health and development issuesfrom stopping the spread of HIV to improving reproductive health and ensuring that young people lead full and productive lives. Through biomedical, social science, and public health research in 50 countries, we work with our partners to deliver solutions that lead to more effective policies, programmes, and technologies that improve lives around the world. Established in 1952 and headquartered in New York, the Council is a nongovernmental, nonprofit organisation governed by an international board of trustees.

Population Council

One Dag Hammarskjold Plaza

New York, NY 10017

USA

Tel: 212.339.0500

Fax: 212.755 .6052

email: pubinfo@popcouncil.org

popcouncil.org

Suggested citation: Population Council. 2015. "ARV-based HIV prevention for women: State of the science and considerations for implementation in Zimbabwe. Report from a provider workshop." New York: Population Council. 


\section{Table of Contents}

Acknowledgements

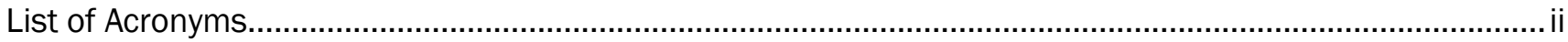

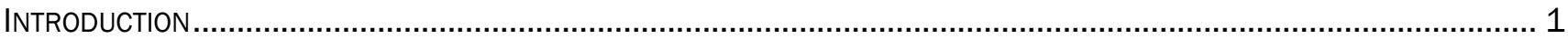

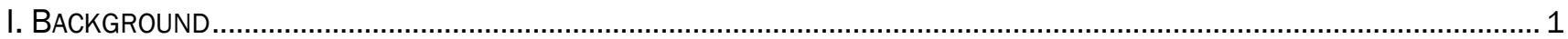

A toolkit for strategic decision-making and planning for microbicides.......................................................... 1

The HIV landscape in Zimbabwe ............................................................................................................... 2

II. RATIONALE FOR A WORKSHOP FOCUSED ON PROVIDERS AND PROGRAMME MANAGERS............................................... 2

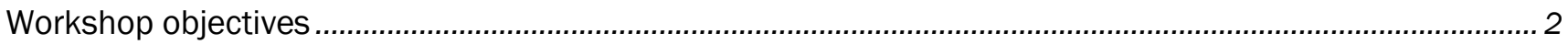

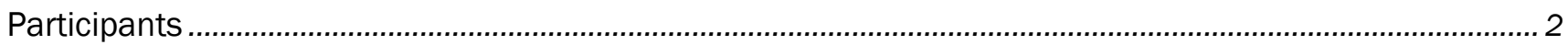

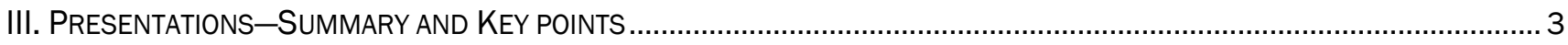

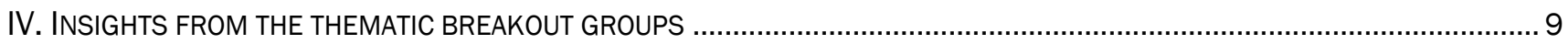

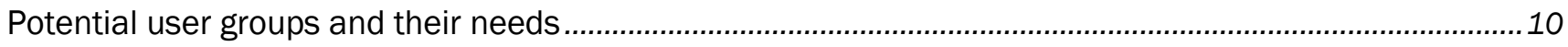

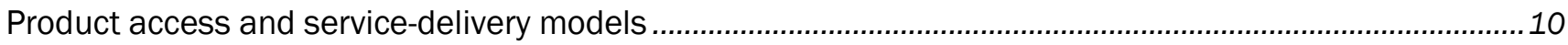

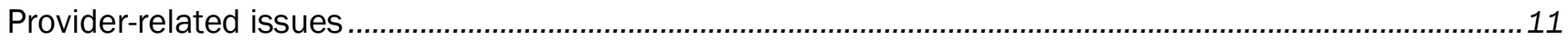

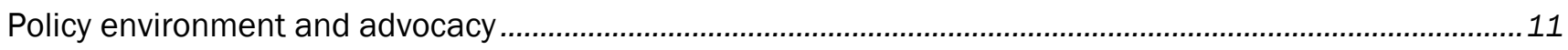

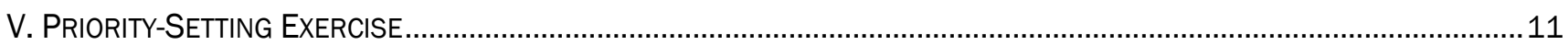

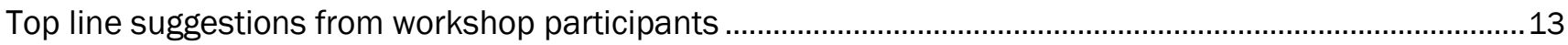

Suggestions from workshop participants on potential product introduction ........................................... 14

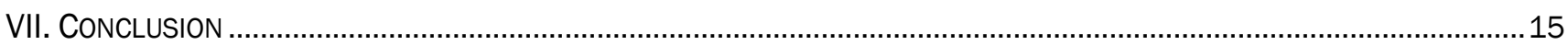

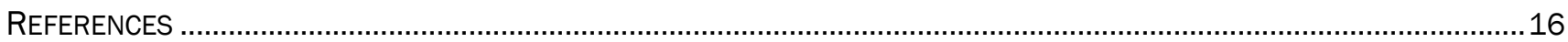

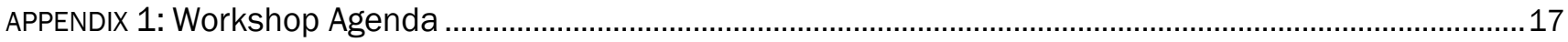

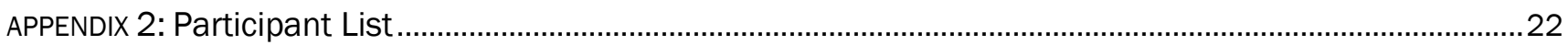

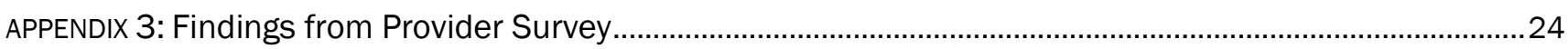

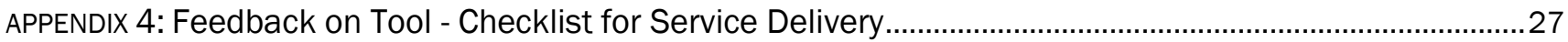

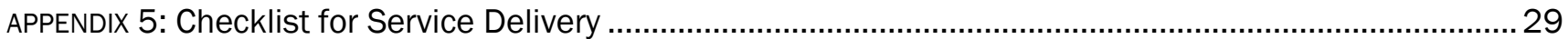

\section{LIST OF FIGURES}

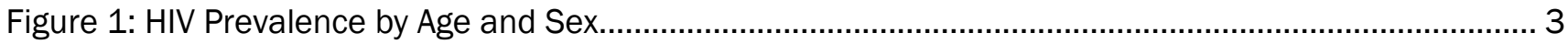

Figure 2: Zimbabwe Combination HIV-Prevention Strategy Priorities ......................................................... 4

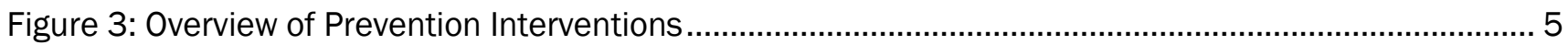

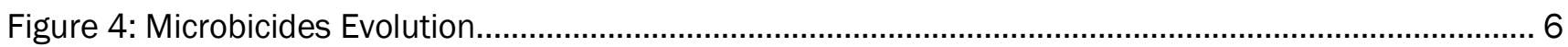

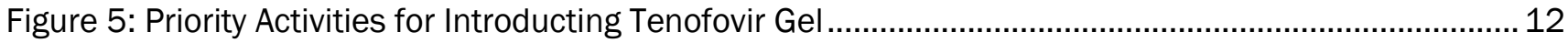

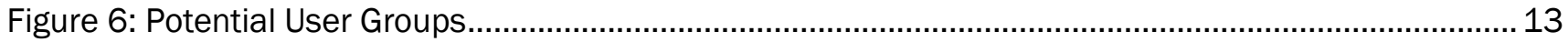




\section{Acknowledgements}

This report was prepared by staff at New Dimension Consulting (NEDICO), including Victoria James, and Population Council staff, Martha Brady, Saiqa Mullick, and Virginia Kallianes.

This document, and insights contained herein, was made possible through the cooperation of the Ministry of Health and Child Care (MOHCC), especially the AIDS and TB Unit. Specific acknowledgements are extended to Dr. Owen Mugurungi (Director, AIDS and TB Unit), Dr. Tsitsi Apollo (Deputy Director, HIV/AIDS and STIs), and Ms. Gertrude Ncube (National HIV Prevention Coordinator). Acknowledgements are further extended to all Provincial Health Service Providers as well as Civil Society Organisations (CSOs) and other partners who were represented in the workshop. Specific acknowledgements are extended to UZ-UCSF (Professor Mike Chirenje and Dr. Nyaradzo Mugodi), the National AIDS Council (Mr. Amon Mpofu), the Zimbabwe National Family Planning Council (Dr. Edmore Munongo), UNICEF (Dr. Tonderai Murimwa), and the UZ-College of Health Sciences (Dr. Tsitsi Magure and Dr. Joconiah Chirenda). 


\section{List of Acronyms}

\begin{tabular}{|c|c|}
\hline ANC & Antenatal care \\
\hline ART & Antiretroviral therapy \\
\hline ARV & Antiretroviral drugs \\
\hline $\mathrm{BCC}$ & Behaviour change communication \\
\hline CAPRISA & Centre for AIDS Programme of Research in South Africa \\
\hline $\mathrm{CHW}$ & Community health worker \\
\hline CSW & Commercial sex worker \\
\hline FACTS & Follow on Consortium on Tenofovir Studies \\
\hline FP & Family planning \\
\hline HCT & HIV counseling and testing \\
\hline IDI & In-depth interview \\
\hline IEC & Information, Education, and Communication \\
\hline KOL & Key opinion leader \\
\hline MCAZ & Medicines Control Authority of Zimbabwe \\
\hline $\mathrm{MCH}$ & Maternal and child health \\
\hline MMC & Medical male circumcision \\
\hline $\mathrm{MNCH}$ & Maternal, Neonatal, and Child Health \\
\hline $\mathrm{MOHCC}$ & Ministry of Health and Child Care \\
\hline МoТ & Modes of Transmission \\
\hline MSM & Men who have sex with men \\
\hline МTCT & Mother-to-child transmission \\
\hline MTN & Microbicides Trials Network \\
\hline NAC & National AIDS Council \\
\hline NGO & Nongovernmental organisation \\
\hline NRTI & Nucleotide reverse transcriptase inhibitor \\
\hline $\mathrm{PHC}$ & Public health centre \\
\hline PICT & Provider-initiated counseling and testing \\
\hline РМТСТ & Prevention of mother-to-child transmission \\
\hline PrEP & Pre-exposure prevention \\
\hline RCT & Randomized controlled trial \\
\hline SRH & Sexual and reproductive health \\
\hline TASP & Treatment as prevention \\
\hline TFV & Tenofovir gel \\
\hline VOICE & Vaginal+Oral Interventions to Control the Epidemic \\
\hline VMMC & Voluntary male medical circumcision \\
\hline WASN & Women and AIDS Support Network \\
\hline YFC & Youth Friendly Centre \\
\hline ZDHS & Zimbabwe Demographic and Health Survey (2010-11) \\
\hline
\end{tabular}




\section{INTRODUCTION}

This report provides an overview of the presentations and discussions emerging from a Provider Workshop on ARV-Based HIV Prevention for Women: State of the Science and Considerations for Implementation in Zimbabwe convened by the Ministry of Health and Child Care (MOHCC) and the Population Council in Harare in May 2014.

The workshop in Zimbabwe is part of a broader global process to begin paving the path for microbicides introduction while awaiting the results of the ongoing confirmatory trial (FACTS 001) of tenofovir gel in South Africa. USAID is spearheading a global effort towards a "Shared Vision and Strategic Plan for Microbicide Introduction." To learn about potential models of introduction, the development of a strategic decision-making and planning tool was considered a priority.

\section{Background}

After 20 years of microbicides research in which half a dozen products were tested in large-scale trials that yielded negative or equivocal results, $1 \%$ tenofovir gel (TFV) has been the first vaginal microbicide gel to show promise. Tenofovir, a nucleotide reverse transcriptase inhibitor (NRTI) used orally for treatment, was tested as a vaginal gel formulation by the Centre for AIDS Programme of Research in South Africa (CAPRISA) in the CAPRISA 004 trial [Abdool-Karim et al., 2010]. The randomized, placebo-controlled, double-blind trial demonstrated that women assigned to 1\% TFV gel had a 39\% lower risk of HIV infection compared with women in the placebo arm. In addition, the gel was even more protective for women who used it in more than $80 \%$ of sex acts; in these high adherers, reduced risk of HIV was 54\% [Abdool-Karim et al., 2010].

\section{A toolkit for strategic decision-making and planning for microbicides}

With the support of USAID/Washington, the Population Council has been engaged in the development and testing of a Toolkit for Strategic Decision-Making and Planning for Microbicides. The toolkit was designed to assist policymakers and programme managers to plan for the introduction and initial roll-out of TFV gel or other ARV-based HIV-prevention technologies (and accompanying services) within existing programmes in a manner that supports high-quality integrated services and explicitly takes into account the epidemiologic context and capacity of the health system, whatever the setting. The toolkit is being piloted in India and Zimbabwe but is designed to be applicable to introducing a wider range of prevention technologies. The toolkit consists of three modules:

Module 1. Landscape Analysis: An analysis of the epidemiologic context of the HIV epidemic, along with an HIV policy and programme scan. This consists primarily of a desk review of available literature and data, supplemented as needed with input from experts familiar with the HIV epidemic and the specific country context.

Module 2. Discussion Guide for Key Opinion Leaders (KOLS) and Decision-Makers: A guide to conducting in-depth interviews (IDIs) with a small group of key decision-makers who will be involved in or influence strategic decisions about the introduction and roll-out of TFV gel. Results will provide an indication of the strategic role TFV gel could play within a country's HIV-prevention programme and help determine how best to continue to explore and plan for introduction.

Module 3. Programme Planning Guide: The Module 3 tool is to be used with providers and programme managers to consider service design for product introduction. Module 3 guides workshop participants to consider the feasibility of introducing HIV-prevention tools, including TFV gel, in specific facility-based settings. It guides users through a series of design considerations to determine opportunities and 
challenges in service setting(s) that should be addressed in programme planning. A "facility checklist" to be used in tandem with Module 3 was also developed.

\section{The HIV landscape in Zimbabwe}

With a prevalence rate of 15\% [ZIMSTAT/ICF, 2012], Zimbabwe has a generalized HIV epidemic in which heterosexual intercourse accounts for $93.95 \%$ of infections [ZIMSTAT/ICF, 2012]. Vertical transmission (from mother to child) is the second most common route of transmission, accounting for $5 \%$ of infections [NAC/UNAIDS/World Bank, 2011]. In 2009, women and girls represented 56\% of the 1.6 million people living with HIV. Young women are disproportionately affected: infection rates among 15-24-year-old females are approximately three times higher than in males of the same age [UNAIDS, 2010].

Given the feminization of the epidemic, where prevalence in women aged $15-49$ years is $18 \%$ compared with $12 \%$ among men aged $15-49$ years, there is a great need for vaginal microbicides or other femalecontrolled methods that women can use to help reduce their risk of HIV infection. Clinical trials of vaginal microbicides have been conducted in Zimbabwe since the 1990s. Zimbabwe is a key country in subSaharan Africa with a generalized epidemic and a commitment to microbicide introduction.

\section{Rationale for a workshop focused on providers and programme managers}

Recognizing the important gate-keeping role that service providers and programme managers play in fostering, or impeding, access to new HIV-prevention tools, their approval and "adoption" is critical for the success of any product. Gathering their insights about service-delivery strategies to incorporate HIVprevention technologies was deemed essential. Specifically, the workshop sought to obtain providers and program mangers' input into the design of appropriate services for tenofovir gel, should it be introduced into the country.

The workshop was preceded by a series of in-depth interivews with KOLs in Zimbabwe, the majority of whom suggested that working directly with programme managers and providers was a critical next step in preparing health systems for product introduction. Although some KOLs were concerned about widespread communication with the public before results of the FACTS 001 confirmatory trial are available, the majority recommended bringing providers into the discussion earlier rather than later.

\section{Workshop objectives}

- To explore the feasibility of new HIV-prevention product introduction in diverse service-delivery settings through dialogue with health service providers;

- To gather input from programme managers and representatives of provider professional associations (i.e., nurse/midwives, OB/GYNs, pharmacists, etc.) about a range of programmatic issues related to introducing HIV-prevention products for women, including TFV gel if proven effective.

\section{Participants}

The workshop brought together 78 participants representing the spectrum of agencies engaged in HIV prevention in Zimbabwe, including: health service providers from 10 districts, civil society representatives, researchers, international NGOs, academics, and others. 


\section{Presentations-Summary and Key points}

This section provides a summary of selected presentations and key points emerging from discussions at the workshop.

Welcome and Official Opening (Dr. Tsitsi Apollo, Deputy Director HIV/AIDS and STIs, Zimbabwe Ministry of Health and Child Care)

The workshop was officially opened by Dr. Tsitsi Apollo who provided welcoming remarks and acknowledged the broad range of participants and institutions at the workshop. Dr. Apollo acknowledged financial support from USAID as well as technical support from the Population Council and reiterated the Ministry's openness to dialogue and partnership in addressing challenges affecting the health sector.Dr. Apollo stressed that the overall 15\% HIV prevalence in Zimbabwe remains unacceptably high and that data showing the heightened vulnerability of women and girls to HIV infection confirms the need for dialogue on prevention options for women. Evidence from the ZDHS (2010-11) shows that among women aged $15-49$, prevalence is $18 \%$ compared with $12 \%$ among men aged 15-49. Figure 1 shows HIV prevalence by age and the disparity in prevalence rates for women and men, as indicated by the ZDHS 2010-11.

Figure 1: HIV Prevalence by Age and Sex

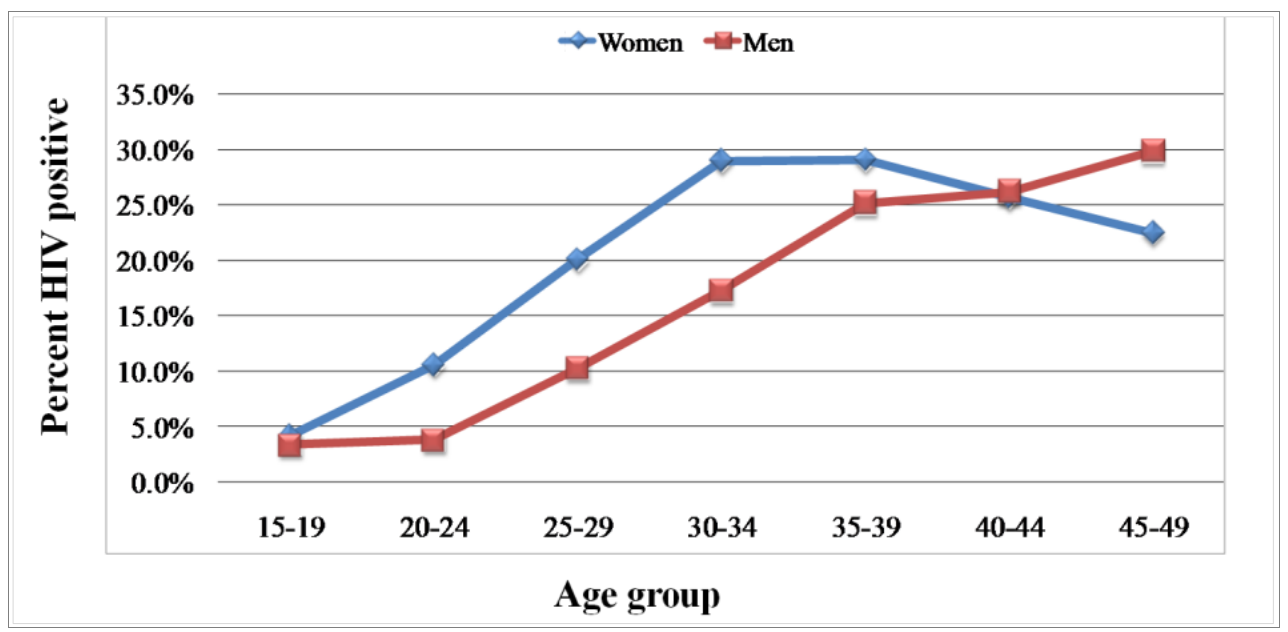

Source: ZIMSTAT and ICF International, 2012. Demographic and Health Survey (DHS)

Dr. Apollo reminded workshop participants of Zimbabwe's key role in the microbicide field through active engagement and pioneering work in research and clinical trials. She noted that Zimabwe should not lag behind on implementation. Given that ARV-based prevention requires periodic HIV testing, efforts to strengthen health systems' capacity to provide testing and re-testing will be needed. Various models of testing, including home-based testing, will need to be tested to determine their feasibility and acceptability. Currently, Zimabawe plans to pilot test different models.

\section{The Need for New HIV-Prevention Methods and Combination HIV-Prevention Strategies (Ms. Gertrude} Ncube, MOHCC)

Ms. Ncube's presentation described the Combination HIV-Prevention Strategy that Zimbabwe developed and is implementing. This is the strategic framework within which dialogue on introducing ARV-based prevention tools/products should be framed. Combination prevention was defined as “...rights-based, evidence-informed, and community-owned programmes that use a mix of biomedical, behavioural, and 
structural interventions, prioritized to meet the current HIV-prevention needs of particular individuals and communities, to have the greatest sustained impact on reducing new infections." Combination prevention has been prioritised in Zimbabwe due to: 1 ) the realization that there is no single "magic bullet" for HIV prevention; 2) the need to optimize combined effects of interventions; 3) the importance of offering different options to people; and 4) the efficiencies of integrated delivery. As shown in Figure 2, combination prevention is underpinned by coordinated behavioural and biomedical strategies for HIV prevention.

\section{Figure 2: Zimbabwe Combination HIV-Prevention Strategy Priorities}
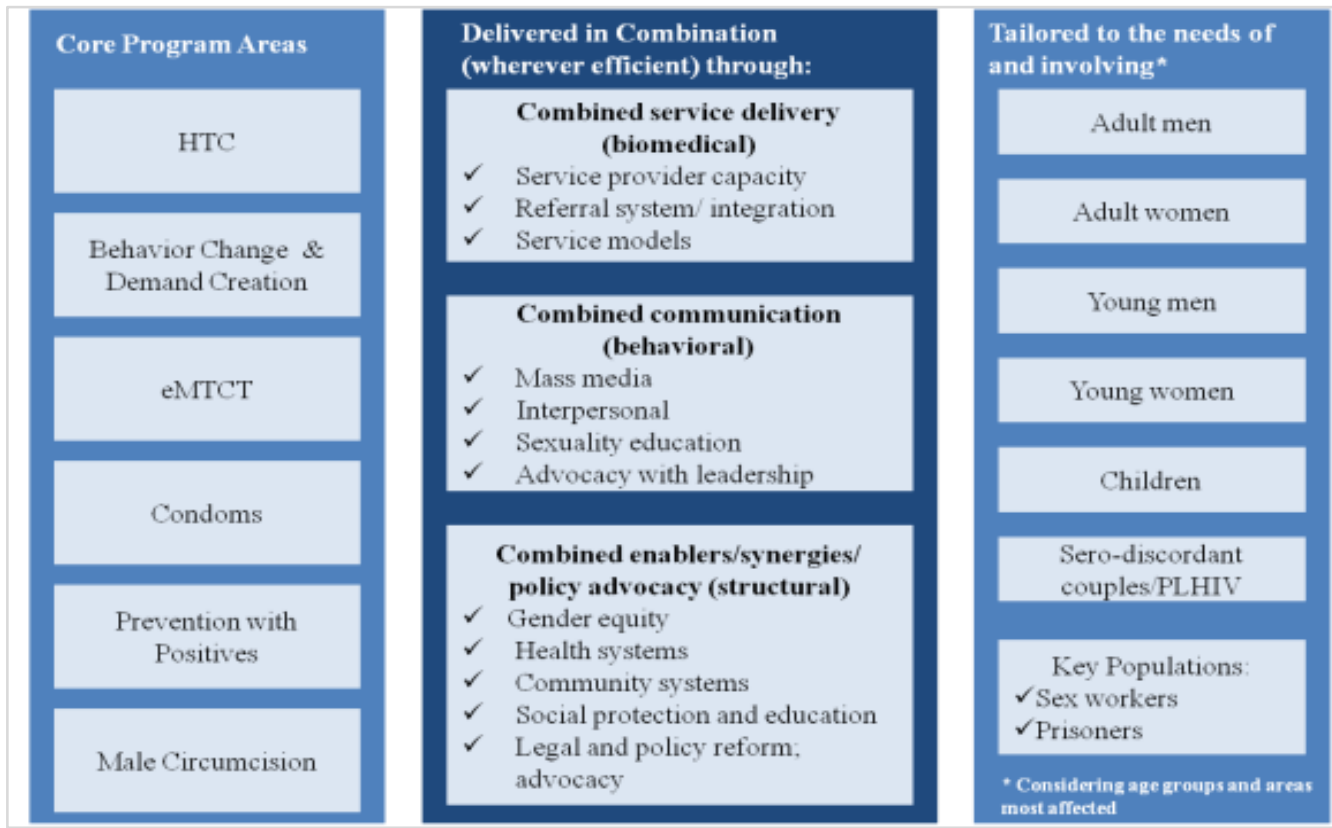

Ms. Ncube outlined the "HIV transmission highway," based on evidence from the Modes of Transmission (MoT) study, which cited: serial casual relations, frequenting sex workers, high levels of STIs (in particular HSV-2), cross-generational sexual relations, mother-to-child transmission (MTCT), and early sexual debut as contributing towards HIV transmission. Multiple concurrent partnerships (MCP), combined with low condom use and low risk perception among those in long-term relationships, as well as low levels of male circumcision are additional factors.

While there has been a decline in HIV prevalence worldwide as a result of behaviour-change interventions, preventing HIV infections remains the most important measureof controlling the epidemic. It is crucial to direct efforts towards interventions that are appropriate to the type of epidemic in each setting. As new evidence emerges, support of new interventions will be needed; these may include pre-exposure prevention (PrEP) as part of combination HIV prevention. Existing HIV-prevention interventions are shown in Figure 3, illustrating that microbicides for women (noted in white) remain a missing piece in the menu of interventions. 
Figure 3: Overview of Prevention Interventions

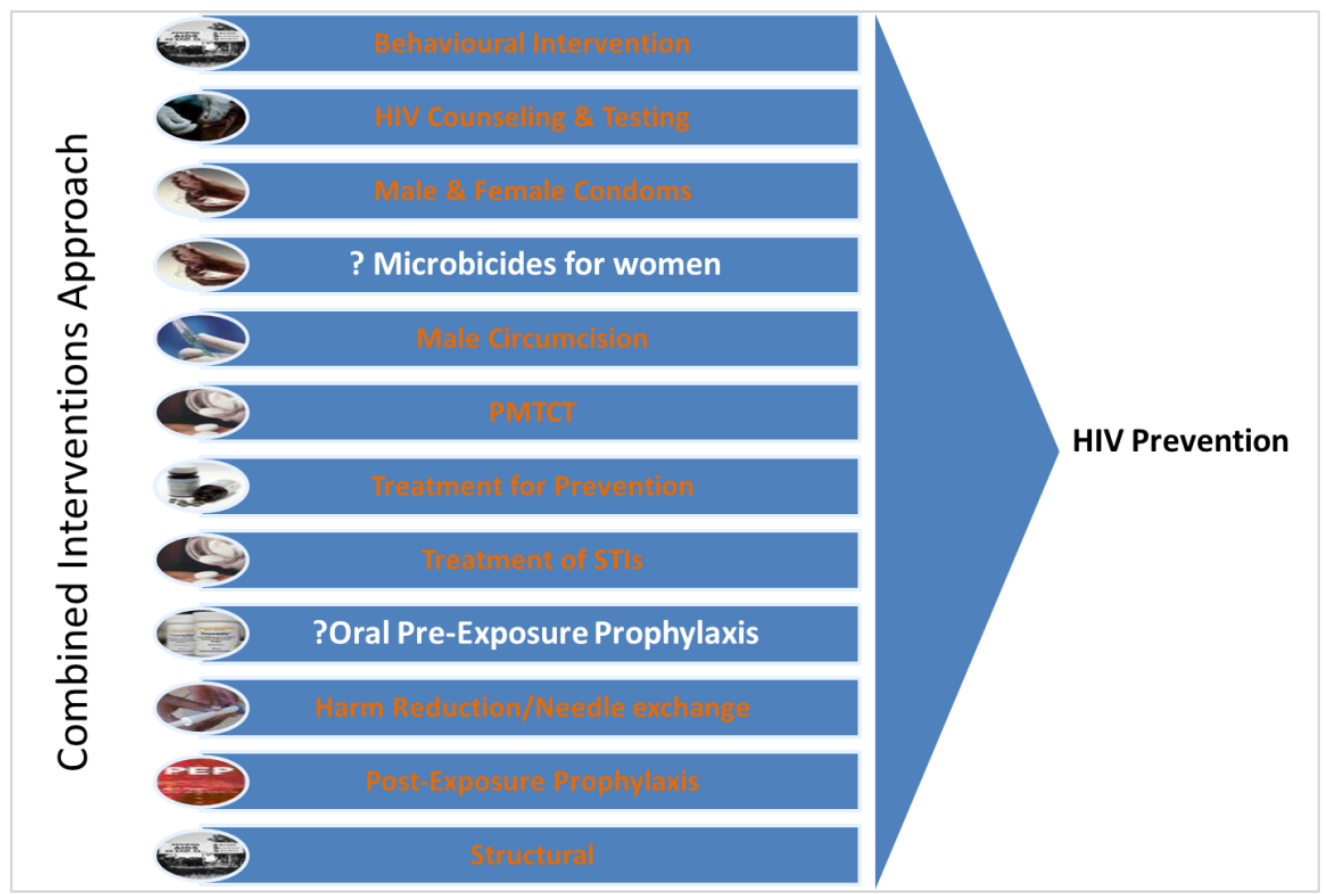

\section{New HIV-Prevention Methods and Combination HIV Prevention with a Focus on PMTCT (Dr. Tonderai Murimwa, UNICEF)}

Dr. Murimwa outlined the epidemiology of HIV in Zimbabwe and described relevant maternal, neonatal, and child health (MNCH) indices. An estimated 156,718 children 0-14 years are living with HIV in Zimbabwe; the MTCT rate was estimated at $18 \%$. The Elimination of MTCT Strategy, PMTCT Programme results of 2013, and Option B+ for PMTCT programmes were presented.

The Zimbabwe prevention of mother-to-child transmission (PMTCT) package of care includes antenatal care, universal HIV counselling and voluntary testing, partner involvement in counselling, provision of antiretroviral (ARV) prophylaxis, safe delivery, postnatal care for infants, and counselling on safe breastfeeding practices. MNCH indices based on ZDHS (2010-11) findings concluded that 90\% of pregnant women received antenatal care (ANC) (ZDHS 2010-11)1. An estimated 43\% of women reported attending a postnatal care (PNC) visit by six weeks, which presented a missed opportunity for PMTCT. Nearly one-third (31\%) of children are reported to be exclusively breastfed. The Option B+ strategy is based on the recommendation that all HIV-positive pregnant and breastfeeding women should initiate triple ARVs (ART), which should be maintained at least for the duration of MTCT risk. In addition, women meeting treatment eligibility criteria should continue lifelong ART. Option B+ treatment involves triple ARVs (ART) for life for any woman diagnosed HIV-positive in pregnancy irrespective of WHO clinical stage or CD4 count. Despite the benefits of Option B+, some issues remain, including: readiness and willingness to adhere to lifelong ART (women must not feel "coerced" to be on lifelong ART); inconvenience of lifelong treatment; cost to the programme; risks of ART-toxicity, resistance, or drug interactions. It was noted, however, that improvements in potency, toxicity profile, and tolerability (including reduced pill burden) allow for durable viral suppression for most patients.

1 First trimester (3 months)-19\%, average gestational age at booking is 25 weeks (6 months+) and 4 or more ANC visits-65\%. 


\section{Overview of Future ARV-Based Products: Microbicide Gels and Vaginal Rings (Professor Mike Chirenje, UZ- UCSF))}

This session provided the audience with a technical update on ARV-based gels and rings, emphasizing the ongoing trials in South Africa and Zimbabwe and timelines for results, including potential benefits in the Zimbabwean context. Dr. Chirenje provided an overview of the types of microbicides in development and on the horizon, as well as a review of ongoing research on their safety and efficacy. The history of microbicide development starts with the $1^{\text {st }}$ generation surfactants, $2^{\text {nd }}$ generation polymers, $3^{\text {rd }}$ generation ARVs, and leads up to the $4^{\text {th }}$ generation receptor blockers. Some of this history is shown in Figure 4. Multiple products have been tested over nearly two decades, leading up to the landmark results of the CAPRISA 004 1\% tenofovir gel trial in 2010.

\section{Figure 4: Microbicides Evolution}

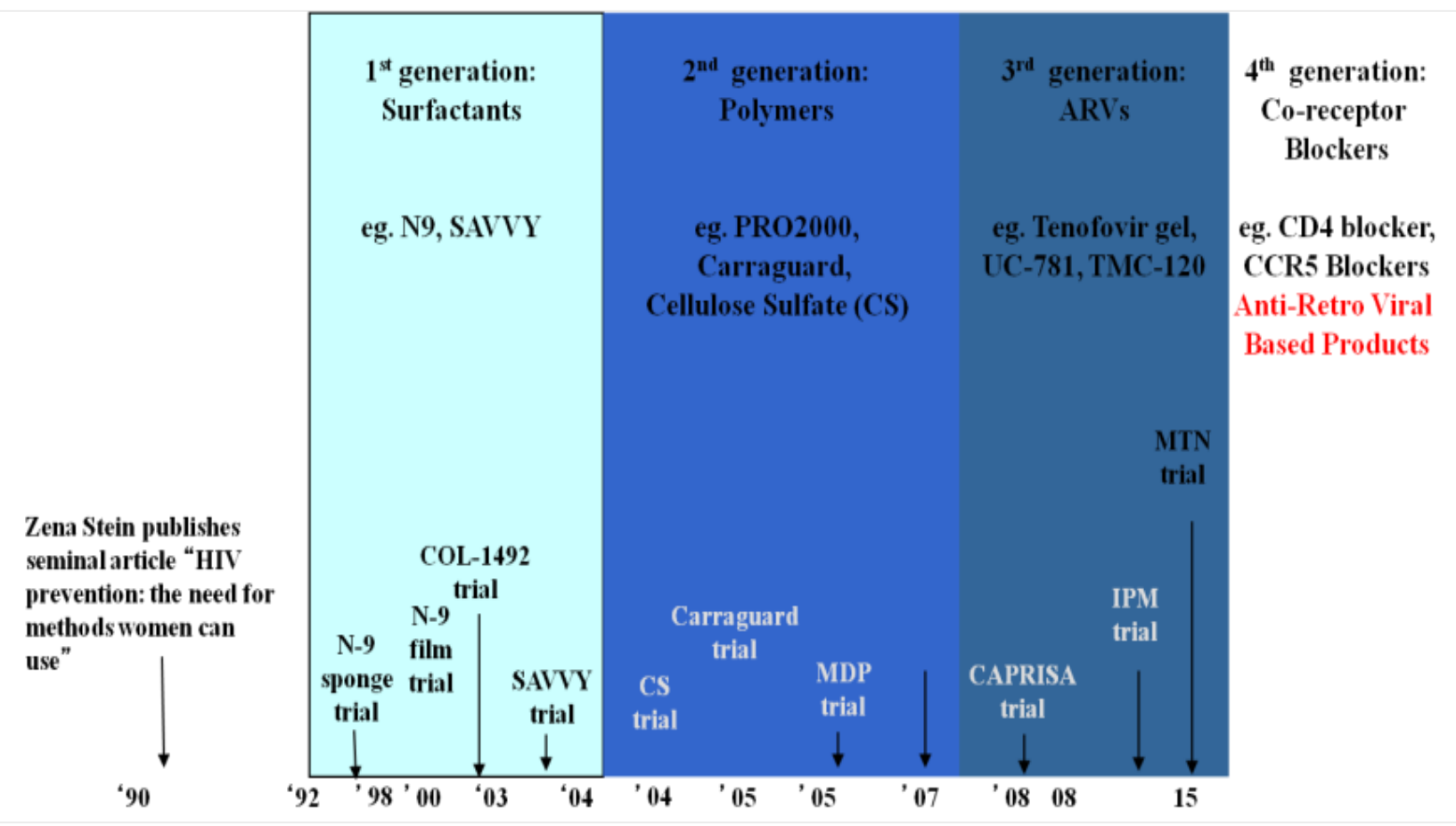


Topical microbicides under development can be in the form of a cream, suppository, film, or gel. Currently, tenofovir (TFV) gel is being used in the form of a $1 \mathrm{ml}$ intravaginal dose providing $40 \mathrm{mg}$ of TFV. CAPRISA 004 (Centre for AIDS Programme of Research in South Africa) was a Phase $2 b$ trial in South Africa that tested the safety and effectiveness of $1 \%$ tenofovir gel for the prevention of HIV in women. The trial used the BAT 24 regimen that requires women to insert the gel up to 12 hours before sex or as soon as possible within 12 hours after sex. The results showed 39\% gel effectiveness, while additional results showed the gel as even more effective with greater adherence to the regiment. There was a 54\% reduction in HIV among women who followed the regimen most closely. Importantly, no resistance to tenofovir was identified. The gel was also found to be safe in Hepatitis B-infected women. The study found no evidence of risk compensation or behavioural disinhibition. There was also a $50 \%$ decrease in HSV-2 infections among the women who were randomized to the tenofovir gel cohort.

After the CAPRISA 004 trial, the VOICE (Vaginal+Oral Interventions to Control the Epidemic) study was conducted in South Africa, Uganda, and Zimbabwe. VOICE was a Phase $2 b$, randomized, double-blind, placebo-controlled, five-arm trial of daily use of vaginal 1\% TFV gel, oral TFV (TDF), and oral tenofovir/emtricitabine. The VOICE study did not confirm the CAPRISA 004 result of 39\% protection. Another study of 1\% tenofovir gel, FACTS 001 (Follow on Consortium on Tenofovir Studies) is underway in South Africa, with results expected in early 2015.

\section{$\underline{\text { Additional Technologies }}$}

Dr. Chirenje noted current efforts to test the efficacy of various other HIV-prevention technologies, including the dapivirine intravaginal ring. The ring is being tested in South Africa and Uganda, and at Microbicide Trials Network (MTN) study sites in Malawi, South Africa, Uganda, and Zimbabwe. In addition, an HPTN 076 study will evaluate the safety of an injectable product (TMC278 LA; 1,200 mg dose) in women in sites in sub-Saharan Africa and the United States. Dr. Chirenje concluded with a brief

\section{Questions and Answers}

Selected questions from workshop participants:

- Question: What are the effects of tenofovir on pregnancy and lactation?

Response: No transfer of tenofoivir from the placenta to the baby was seen in previous trials.

- Question: Does the ring have an applicator?

Response: The ring does not have an applicator. It has been designed to be inserted by the fingers, similar to the female condom.

- Question: Does it stay in place? What happens during menstruation and intercourse?

Response: The ring stays in place, including during intercourse. It is made from silicone and most men can hardly feel it.

- Question: How are we dealing with women who are taking placebos?

Response: This is a randomized controlled trial (RCT) in which a researcher does not know which women are using a placebo or the actual product. However, the women are told beforehand that they are getting an active or a nonactive ring.

- Question: Why was Harare chosen as a site (Spilhaus Clinical Research Site) and why were samples from rural areas not selected?

Response: It is complex to set up a research site. It requires elaborate tests and involves a complex process; hence the decision to choose Spilhaus was based on the capacity.

- Question: What are the cost implications for women? Response: Effort is being made internationally to make the product available to "ordinary" women.

- Question: What has been women's take on the issue of dry sex and use of the gel?

Response: Actually it seems from the studies that people actually prefer more lubrication rather than dry sex. However, generally women tend to over clean the vaginal area, which leaves it too dry and vulnerable.

- Question: What interventions are there with regard to women getting infected during the time they are breastfeeding their infants?

Response: All mothers are tested when registering for the antenatal clinic. After that they get tested three times.

- Question: What is the HIV status of the men and women who are in these studies?

Response: We enroll men and women who are negative and monitor them if they acquire the virus during the trial.

- Question: Are these gels all-encompassing or do we also need to stress the use of condoms?

Response: It would be unethical to enroll women in the study and not give them access to condoms since condoms are tried and tested.

- Question: How do you measure the efficiency of the ring? Response: We use randomization, i.e., if everything is the same except an active or inactive ring, then the only answer is the ring.

- Question: It seems men are a stumbling block. What are we doing to involve them?

Response: We always encourage our participants at the beginning to involve their partners in the studies. 
reflection on the timeline and investments made so far towards an anti-HIV vaccine.

\section{Key Opinion Leader Insights: Results from Zimbabwe Study (Dr. Saiqa Mullick, Population Council)}

Dr. Mullick reported on the results of a qualitative study among KOLs in Zimbabwe. The objective of the study was to gather perspectives on key policy and programmatic issues to inform the introduction of $1 \%$ tenofovir gel should it be shown effective. A total of 18 in-depth interviews with leading opinion leaders in Zimbabwe were conducted using a standardized discussion guide and analyzed by the Population Council research team. The opinion leadersrepresented a broad swath of stakeholders including government, regulatory agencies, NGOs, academia, civil society, professional associations, and donor agencies. Selected findings regarding key themes are presented here.

\section{Efficacy}

Most respondents believe that a "recommended level of efficacy" should be reached before approval of TFV gel. A few felt that "any level of efficacy would be sufficient," given that there is no currently available ARV-based prevention option for women. About one-third believe that the gel would not be worth introducing unless it is at least 50-60\% effective, comparable to male circumcision; a few were of the opinion that the $39 \%$ level of efficacy shown in the CAPRISA 004 trial would be sufficient.

\section{Safety}

The majority of respondents believe that TFV gel for HIV prevention is important, but that product safety is of paramount importance. Concern about safety of the gel in different populations, for example, in pregnant women and in adolescents, was voiced by several respondents. Some recommended that separate safety studies among adolescents be conducted. Most respondents were not concerned about (or did not mention) fertility as an issue, although two noted that any impact on fertility would limit uptake.

\section{$\underline{\text { Intended users }}$}

From a public health and cost-effectiveness standpoint, most respondents felt that TFV gel would yield optimum results if focused on women at highest risk, especially young women, sex workers, married women who are unsure of husband's status, and women with multiple partners. In addition, serodiscordant couples were identified as a potential user group, although identifying such couples was considered by many to be challenging. The majority of respondents identified young women as a high-risk group, given that HIV incidence is highest among the 20-24-year-old age group, thereby making them a logical priority for tenofovir gel.

\section{Where should tenofovir gel be offered?}

Respondents stressed that tenofovir gel should be available in both the public and private sector and recommended that distribution should start through primary health centres (PHCs) and nongovernmental organisations (NGOs). Another recommendation was to ensure the gel be introduced through both family planning/sexual and reproductive health (FP/SRH) services and HIV-prevention programmes. Placing tenofovir gel within primary health or SRH services was viewed as less stigmatizing and more routine. 
Lessons learned from past and current HIV-prevention programmes, advocacy, and community engagement activities (Dr. Joconiah Chirenda, University of Zimbabwe, Community Medicine)

This presentation provided historical background on infectious-disease prevention and control, chain of infection, and HIV prevention. The focus was on the importance of surveillance and response, which facilitates detection, investigation, and monitoring of infections. Prevention and control of infectious diseases requires applied research, infrastructure, and training. Dr. Chirenda highlighted the importance of building on existing infrastructure to generate prevention and control strategies that are context specific, and the need to learn from interventions from other programmes. He called for the building of multidisciplinary teams of social scientists, health economists, clinicians, public health practitioners, and civil society to examine new technologies and interventions before their adoption.

\section{The Policy Environment in Zimbabwe (Mr. Amon Mpofu, National AIDS Council)}

This presentation highlighted Zimbabwe's constructive policy environment with respect to HIV and AIDS. The National AIDS Trust Fund was described as a model for resource mobilization. Mr. Mpofu noted that new interventions proven to be efficacious have received support from Parliamentarians, citing the example of voluntary medical male circumcision (VMMC). Due to the favourable policy environment and strong partnerships, the National AIDS Council (NAC) has managed to survive in an economically constrained context and has achieved good results. NAC's role in product introduction would likely involve disseminating information on the product after proper authorization, and ensuring that products are integrated into existing HIV-prevention programmes.

\section{Widening the scope of Family Planning to include HIV-prevention strategy (Dr. Edmore Munongo, ZNFPC)}

Dr. Munongo noted that the family planning (FP) programme in Zimbabwe, begun in 1953 by volunteers, has expanded tremendously over the past 30 years. He provided background on the Zimbabwe National Family Planning Council (ZNFPC), established in 1985. ZNFPC is supported by the MOHCC, IPPF, UNFPA, NAC, DFID, USAID, Crown Agents, PSI, PSZ, UZ, MCHIP, and UNICEF. Key programmes run by ZNFPC include: 1) community-based distributor (CBD) programme; 2) adolescent sexual and reproductive health (ASRH); 3) Delivery Team Top Up (DTTU); 4) training, marketing, and communication; 5) evaluation and research, along with overall support to the health sector.

Through its FP programmes, ZNFPC has made important contributions to the HIV response, although gaps remain. There is still an unmet need for family planning, particularly among adolescents and those hard to reach. ZNFPC faces challenges including limited funding, high staff attrition, low uptake of permanent FP methods, and limited storage space for FP commodities, among others. Dr. Munongo concluded with recommendations on intensifying advocacy on the importance of RH/FP in improving maternal and child health, reduction of HIV and poverty alleviation, integration of RH/FP and HIV/AIDS to ensure comprehensive services, support of effective community-based interventions to increase access to services as well as prioritising policy support to improve access to RH/FP services, particularly access by vulnerable groups and in particular youth and HIV-positive people.

\section{Insights from the thematic breakout groups}

Following these presentations by leading experts, the meeting was organised around critical themes that were reviewed and debated in breakout groups. During lively discussion and debate, meeting participants worked to identify key issues related to key populations, potential product access and service delivery 
channels, provider-related issues, and the larger policy environment. Each breakout session led to robust discussions, the results of which are briefly highlighted below.

\section{Potential user groups and their needs}

Participants felt that TFV gel has clear benefits in terms of reducing risk, providing women with an option under their control, and offering the conveniencece of use only when needed. The gel is likely to benefit many types of women including: married women, sex workers, adolescents, and women in sero-discordant relationships. Essentially, the group felt that all sexually active women "at risk" would potentially benefit. There was considerable discussion around the possibility of marketing the gel to men and learning more about men's perspectives.

The potential barriers to introduction of TVF gel were identified as: lack of knowledge by users, discomfort with testing, concerns around stigma, cost (especially in the context of high levels of poverty), limited provider knowledge, negative provider attitudes, community perceptions, product availability and supply chain issues, and challenges related to adherence.

\section{Product access and service-delivery models}

There was a general diccusion around the need to strengthen health systems' capacity to provide HIV testing and re-testing. Participants suggested several possible delivery models for TFV gel, including the following.

PMTCT and ANC services are considered important entry points given that women are already accessing these services. Adding microbicides information-and, as appropriate, product-could provide an integrated approach to service delivery.

Voluntary Testing and Counseling Centres could play a pivotal role, as they have an existing servicedelivery infrastructure. These centres provide scope to work with a variety of organisations with potential distribution networks.

Youth Service Centres currently distribute commodities (condoms) and could potentially add TFV gel to that existing distribution network, as and when appropriate.

The group also considered potential challenges for introduction. For example, adding a new product into health services can tax an already overburdened workforce. The required testing could pose challenges, as clients may be averse to retesting in order to get resupply of gel. Home testing remains controversial because modalities around counselling are yet to be defined. However, it was noted that the government will conduct pilot studies to determine the feasibility of home testing. Participants further noted that stigma and discrimination may pose a problem, as communities may have negative (and/or ill-informed) perspectives about the gel.

Finally, it was noted that the Ministry of Health has an Advocacy and Communication Strategy that facilitates communication from the grassroots to Parliamentarians; that strategy could be used to disseminate information on new technologies. In addition, there is a need to focus on leveraging existing approaches for demand creation.

The group recommended:

- Training of health workers and distributors on use of the gel

- Working with partners, such as ZNFPC and NAC, as well as organisations providing VCT and PMTCT services

- A phased-introduction approach

- Prioritizing integration within existing strategies. 


\section{Provider-related issues}

An almost unanimous call was made for training of service providers so they can understand the complex issues concerning the gel. It was noted that the confidence of potential users could be affected if service providers cannot provide sufficient information about the gel. Provider competency in communicating the notion of "partial protection" was seen as important. Participants suggested that training should focus on both developing competencies and transforming attitudes. Negative provider attitudes can be a barrier to provision and, consequently, client uptake. This is especially true in the case of products that may be provided to stigmatized groups, such as sex workers. Participants further emphasized the need to focus on both demand- and supply-side components as it could be counterproductive to create demand for a product that is not yet available, and it is difficult to invest in supplying product where demand is low.

The group underscored that service providers for TVF gel should not be too dissimilar from those in the existing structure, particularly since product introduction should encourage and prioritize integration. Given that TFV gel is a medical product, it should be handled by professionals who are able to provide accurate information; nurses, doctors, village/community health workers, and possibly pharmacists, were identified as the most appropriate service providers.

Several questions emerged relating to how other sexual and reproductive health issues will be addressed. Given that TFV gel does not provide dual protection, the group felt it was imperative that the gel be used together with contraceptive method to protect against pregnancy. Questions arose around whether women can use the gel while menstruating or wearing a diaphragm. It was clear that service providers will need adequate training to be able to disseminate correct information.

\section{Policy environment and advocacy}

It was noted that Zimbabwe has a robust policy environment that should be appropriately used for product introduction. The Medicines Control Authority of Zimbabwe is a key institution that should be involved in review and approval prior to full-scale rollout. It was noted that there are several strategic documents that a new product can build upon, and there is further scope to integrate product information into the curricula of health professionals' trainings. Participants emphasized that research will be critical for successful product implementation and that it should focus on product acceptability within the Zimbabwean context as well as on monitoring drug resistance, especially because there has not been sufficient evidence around whether use of TFV gel heightens the possibility of drug resistance. Operational research was considered of high importance and high priority in the process of introducing any new ARV-based product such as TFV gel. Distribution and use of the gel should be planned based on the current context and with a focus on complementing existing HIV-prevention interventions.

\section{Priority-Setting Exercise}

An important component of the workshop was to generate discussion and input around next steps and key activities, particularly from the point of view of service providers (i.e., nurses, medical officers). Most of the service providers $(\mathrm{N}=46)$ in the workshop participated in this exercise. After the thematic breakout sessions, workshop participants were led through a priority-setting exercise. First, participants were asked to create a list of key activities for introduction of TFV gel. They were asked to consider which activities were of most importance and which they felt should be given high priority. A comprehensive listing of activities and potential next steps was generated. Figure 5, visually depicts the range and type of activities identified.

\section{Identifying and Prioritizing Activities for Introduction}

Participants were then asked to define and order activities in terms of importance and priority. While most of the activities were considered important by the majority of respondents, a few were mentioned multiple 
times and continued to emerge in the discussions. For example, almost half felt that sensitization of women, providers, and civil society about the gel was of high importance and a high priority. Health worker training was also considered to be of high importance and high priority by many. Interestingly, research (operational, clinical, and implementation science) was cited by almost all (40) providers as being of high importance and high priority in the process of introducing the gel. The three key areas are depicted in the center circle of this graphic.

\section{Figure 5: Priority Activities for Introducing Tenofovir Gel}

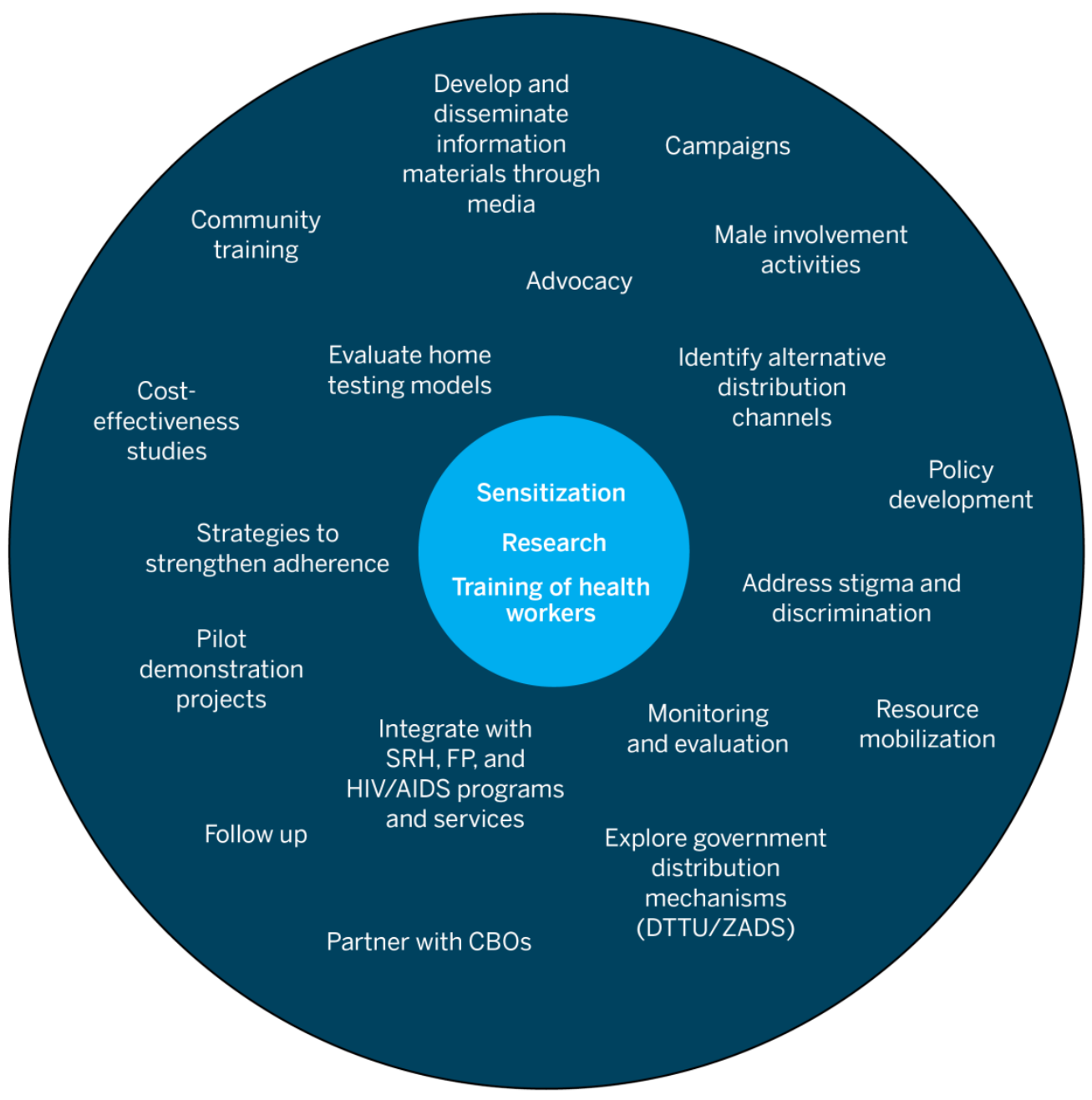

\section{Feedback on Potential User Groups}

Another exercise was to identify and prioritize potential user groups. Service providers outlined user groups they felt would be of importance and priority when introducing TFV gel. Again, while a very broad array of potential users were listed, as noted in the outermost circle of the graphic, a few groups emerged as being both important and a priority. Adolescents were cited as the group that was most important, followed by sex workers. Sex workers were cited as being of highest importance and highest priority by half of the providers. Married women and women in sero-discordant partnerships were also cited as being of high importance and high priority. Figure 6 below depicts the broad range of potential user groups identified by providers. The key populations considered most important were commercial sex workers, married women, discordant couples, and adolescents/young women. 


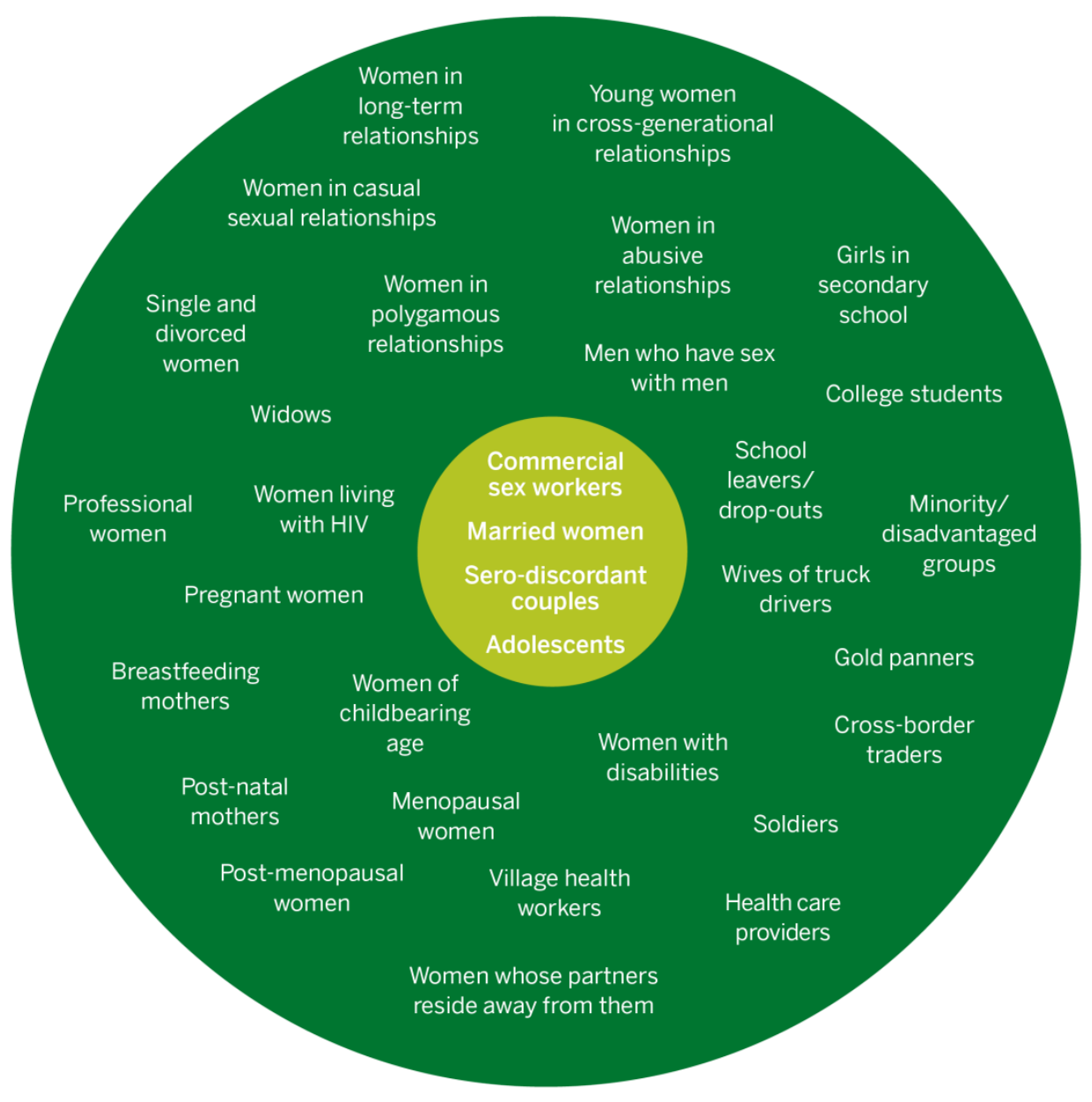

\section{Top Line Suggestions from Workshop Participants}

Throughout the day-and-a-half workshop, insights and information were gleaned from meeting participants. A short, self-administered questionnaire was given to providers at the end of meeting. A brief summary of findings can be found in Appendix 1.

Also as part of the workshop, we requested feedback from providers on a facility checklist that had been developed by the Population Council as part of the broader microbicide toolkit. The tool generated lively discussion. Provider feedback on the facility checklist is summarized in Appendix 2.

Finally, we asked participants for their top suggestions around product introduction. The chart that follows outlines the key suggestions offered by workshop participants. 


\section{SUgGESTIONS FROM WORKSHOP PARTICIPANTS ON POTENTIAL PRODUCT INTRODUCTION}

Focus on integration. Although the products are new, they should add to the existing HIV-prevention package, building on existing HIV-prevention models. Successful introduction and uptake will largely depend on the costeffectiveness of the products, and leveraging existing structures and systems provides scope for achieving optimum results.

Be guided by existing frameworks. The current policy framework around access to information on and commodities for HIV prevention must determine who should access the product and how. In addition, the policy framework should provide sufficient guidance on testing as well as availability and accessibility.

Prioritize availability, accessibility, and affordability (Three As). If a product is proven efficacious, there should be investments to ensure its availability and accessibility to those who need it most. It must be made affordable to targeted groups.

Invest in efforts to determine acceptability of products. There have been some acceptability studies that have concluded the products are acceptable, but these have primarily focused on acceptability within research settings. Full-scale product rollout should be informed by acceptability within the contexts where the product is expected to be used.

Employ a phased approach. Successful introduction will be based on a combination of factors and appropriate staging and sequencing of activities. A phased approach will ensure buy-in and policy support, positive provider attitudes, uptake willingness by women, male support, and supportive communities.

Define and communicate the role of civil society. Civil society has a significant role in the response to HIV in Zimbabwe. Similarly, civil society is likely to play a key role around new product communication, demand generation, and stigma reduction.

Address negative attitudes by health providers. Health providers will play a key role in supporting successful introduction of the product. Positive attitudes by health providers towards the products will likely result in successful uptake.

Utilize lessons from VMMC and other interventions. A new product will be introduced into a context where other interventions have been successfully introduced. Opportunities for leveraging lessons from VMMC, treatment as prevention (TASP), female condom, other SRH interventions will be important, especially with respect to ensuring messages are well segmented and clearly communicate the protective effect.

Communicate appropriately for targeting and segmentation. The product will be made available to different age groups and populations with different characteristics. Communication messages and mediums should be guided by solid evidence and should address the information needs of specific groups using the most appropriate communication mediums. 


\section{Conclusion}

Zimbabwe can build upon its policy and scientific capacity to determine whether tenofovir gel can offer added benefits relative to costs within the evolving context of combination prevention. Both biomedical and behavioural interventions will be needed. On the biomedical side, interventions, including relatively new approaches such as MMC, TASP, and oral PrEP, are currently underway. Overall there was general broad support from stakeholders for tenofovir gel as an HIV prevention technology, pending positive results of the FACTS 001 trial. If Zimbabwe determines that tenofovir gel would be a useful addition to its HIV prevention programme, pilot demonstration projects will be critical to determine the most strategic entry points for introduction. Zimbabwe's momentum in curbing the HIV epidemic, experience with new technologies and clinical trials, and its capacity for operations research makes it a conducive setting for designing and conducting the necessary demonstration projects.

The workshop was successful in stimulating discussion among service providers and programme managers who would have responsibility for implementation of TFV gel if it were approved. The workshop guided participants through a set of service design considerations and questions which must be addressed in any future introduction planning. Engaging providers in the discussion and gathering their input around service design is a critical step towards developing a programmatic action plan, which is a logical next step once results of ongoing research are available. 


\section{References}

Abdool-Karim Q, et al. 2010. Effectiveness and safety of Tenofovir gel, an antiretroviral microbicide, for the prevention of HIV infection in women. Science Sep 3;329(5996):1168-74. doi:

10.1126/science.1193748. Epub 2010 Jul 19.

Cohen MS, et al. 2011. Prevention of HIV-1 infection with early antiretroviral therapy. N Engl J Med Aug 11; 365(6):493-505. doi: 10.1056/NEJMoa1105243. Epub 2011 Jul 18.

FACTS Consortium. Available at: http://www.facts-consortium.co.za/?page_id=83. Accessed June 7, 2014.

Hargrove JW, et al. 2011. Declining HIV prevalence and incidence in perinatal women in Harare, Zimbabwe. Epidemics Jun;3(2):88-94. doi: 10.1016/j.epidem.2011.02.004. Epub 2011 Mar 2.

Microbicide Trials Network (MTN). Understanding the results of VOICE. Available at: http://www.mtnstopshiv.org/node/2003. Accessed June 6, 2014.

Obiero J, et al. 2012. Vaginal microbicides for reducing the risk of sexual acquisition of HIV infection in women: Systematic review and meta-analysis. BMC Infect Dis Nov 6; 12:289. doi:10.1186/1471233412-289.

UNAIDS. 2010. Report on the global AIDS epidemic 2010. UNAIDS/10.11E | JC1958E

van de Wijgert J, et al. 2001. Phase 1 trial of the topical microbicide BufferGel: Safety results from four international sites. J Acquir Immune Defic Syndr 1;26(1):21-27.

Zimbabwe National Statistics Agency (ZIMSTAT) and ICF International. 2012. Zimbabwe Demographic and Health Survey 2010-11. Calverton, Maryland: ZIMSTAT and ICF International. 


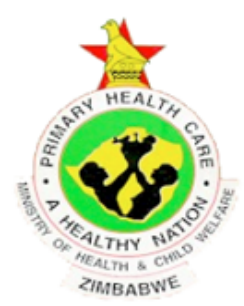

\section{ARV-Based HIV Prevention for Women: State of the Science and Considerations for Implementation \\ Provider Workshop/Zimbabwe Consultation \\ 27-28 May 2014 \\ AGENDA}

\section{Objectives:}

1. Review the state-of-the-evidence around topical PrEP as HIV prevention tool for women

2. Present findings from the Key Opinion Leader Study

3. Facilitate discussion and feedback on potential service delivery channels, user groups, and approaches for introduction of topical PrEP or other microbicides

\section{DAY 1: Tuesday, May 27}

\section{8:30 a.m. \\ Coffee and Registration}

9:00-9:20 a.m.

Welcome and Introductions (Dr. Owen M. Mugurungi)

Welcome participants and thank them for their time, review meetings goals, objectives, and agenda. Comment on the state of the HIV epidemic and prevention in Zimbabwe and this meeting intended to promote discussion around topical PrEP and microbicides.

\section{9:20-9:40 a.m.}

The Need for New HIV Prevention Methods and Combination HIV Prevention (Dr. Tonderai Murimwa)

Present rationale for developing and implementing new HIV prevention methods, in particular women-initiated methods. Briefly review HIV prevention methods currently available - focus on PMTCT. Clarify that this meeting will only cover Topical PrEP recognizing that those methods are part of a larger HIV prevention strategy.

\section{9:40-10:00 a.m.}

The Need for New HIV Prevention Methods and Combination HIV Prevention (Ms. Gertrude Ncube) 
TASP, VMMC, PEP, oral PrEP. Clarify that this meeting will only cover topical PrEP recognizing that those methods are part of a larger HIV prevention strategy.

10:00-10:30 a.m.

Overview of Future Potential ARV-Based Products: Microbicide Gels and Vaginal Rings (Dr. Mike Chirenje)

Provide an overview of microbicide clinical trial findings and ongoing clinical trials, and potential benefit of these technologies. Speaker will give a technical update on ARV-based gels and rings, emphasizing the ongoing trials in South Africa and Zimbabwe and timelines for results, including their potential benefit in the Zimbabwean context.

10:30-11:00 a.m.

Discussion (Facilitator: Dr. Murimwa)

11:00-11:15 a.m. Tea Break

11:15 a.m.-12:00 p.m.

Insights from Key Opinion Leaders in Zimbabwe: Results of a Qualitative Study (Dr. Saiqa Mullick, Population Council)

Provide overview of the Population Council's work to prepare for Microbicide Introduction and Access, under global USAID funding on microbicide preparedness. Present findings from a qualitative study of Key Opinion Leaders in Zimbabwe.

12:15-12:30 p.m.

Discussion (Facilitator - Dr. Samu Dube)

12:30-1:30 p.m.

Lunch

Afternoon Session

Begins with panel on lessons learned from past or current product introduction efforts related to HIV and/ or SRH more broadly.

\section{1:30-2:30 p.m.}

Panel: Dr. Joconiah Chirenda, Dr. Edmore Munongo, Ms. Dagmar Hanisch, Mr. Raymond Yekeye

This expert panel will provide an overview of lessons learned from past and current HIV prevention programs, and what advocacy and community engagement activities have been undertaken to date. Panelists will present findings/insights from experiences related to the introduction of other prevention products from SRH and HIV

2:30-2:45 p.m. Discussion

2:45 p.m. Introduction to Breakout sessions: Goals, Process, Expected Outcomes, Tools (Ms. Ravikanthi Rapiti, Population Council) 
Each breakout session will have a designated facilitator and note-taker. Depending on overall size, the group will be broken down into 4 Working groups in alignment with key themes identified, including:
1) Potential User Groups (User Perspectives): Dr. Nyaradzo Mgodi
2) Product Access and Service Delivery Models: Dr. Tsitsi Magure
3) Provider Related Issues: Cadre, Training, Service Guidelines: Dr. Edmore Munongo
4) Policy and Advocacy: Mr. Sinokuthemba Xaba
I. Potential User Groups and their Needs (Dr. Nyaradzo Mgodi and Notetaker) Facilitator: Ms. Ravikanthi Rapiti
Compare the attributes of topical PrEP and microbicides as different, potential HIV prevention methods for women. For each potential user population (female sex workers, sero-discordant couples, adolescents, women in steady relationships), discuss their HIV prevention needs and interest in using PrEP and/or microbicides.

Sample Questions

- Based on the HIV epidemic, who (what user groups) do you think will benefit most from tenofovir gel?

- What groups should be prioritized? What are the risks and benefits of promoting specifically to these group(s)?

- What do you think will be the key barriers and obstacles for women who wish to access tenofovir gel?

- What strategies can be employed to create demand? Who best to do this?

\section{Product Access \& Service Delivery Models (Dr. Tsitsi Magure and Notetaker)} Facilitator: Dr. Samu Dube

Discuss potential service delivery channels for PrEP and/or microbicides and how these could differ based on user population. What are the opportunities and challenges to address in a program plan for tenofovir gel introduction?

Sample Questions

- Based on the HIV epidemic and health system capacity, which service settings provide good opportunities for implementing Tenofovir gel?

- What is the feasibility of different service delivery channels?

- How will the issue of HIV testing and re-testing be addressed?

III. Provider Perspectives: Training (Dr. Edmore Munongo and Notetaker) Facilitator: Dr. Saiqa Mullick

Consider the types/cadres of providers who should be eligible to provider Topical PrEP. Discuss the current state of provider knowledge, attitudes, and practices around various HIV prevention products and services. 


\section{$\underline{\text { Sample Questions }}$}

- What do you foresee as key challenges providers will face in offering Topical PrEP and microbicides?

- What cadre of provider should provide these products?

- How will other SRH needs be addressed?

- Review and feedback on the Service Delivery/Facility Checklist Tool

IV. Policy Environment and Advocacy (NAC and Notetaker) Facilitator: Ms. Victoria James

Consider the policy, regulatory, and public health implication of introduction TVF gel.

$\underline{\text { Sample Questions }}$

- What additional research is needed in Zimbabwe to guide implementation?

- What are the key messages to communicate to the key audiences (end users, community members, health care providers) about Topical PrEP and microbicides?

3:00-3:30 p.m. Group Work Begins

Resource materials and questions provided to each group

3:30-3:45 p.m. Tea Break

Group Work Continues

4:30-5:15 p.m. Report back

Each group facilitator summarizes key points from the discussions.

5:30 Assignments and Adjourn

DAY 2: Wednesday, May 28

8:30 a.m. Coffee

9:00 a.m. Recap and Synthesis of Day 1 (Dr. Samu Dube)

Facilitator synthesizes key issues to address in introduction and implementation.

9:30 a.m. Discussion and Recommendations: (Professor Mike Chirenje) Facilitator: Dr. Saiqa Mullick

At this point, the group is challenged with answering the following question:

What are the opportunities and challenges to address in a program implementation plan for tenofovir gel introduction? Specifically address each of the following elements:

- Policy environment

- User perspectives and demand creation

- Service provision

- Regulatory, supply chains, logistics, etc. 
Group makes "recommendations" around each of the key program components. Identifies gaps and suggests ways to fill them. A comprehensive list of next steps is prepared and vetted by meeting participants.

\section{1:00-11:15 a.m. Tea Break}

\section{1:15-12:15 p.m. Provider Survey (Population Council) Facilitator: Ms. Victoria James}

In an effort to capture the insights and perspectives of providers, participants will be asked to complete an anonymous self-administered questionnaire.

\section{2:15-12:30 p.m. Closing Remarks \& Wrap Up (Dr. Owen Mugurungi)}

\section{2:30-1:30 p.m. Lunch}

\section{Adjourn}




\section{PARTICIPANT LIST}

\section{ARV-Based HIV Prevention for Women: State of the Science and Considerations for Implementation Provider Workshop/Zimbabwe Consultation 27-28 May 2014}

Ministry of HeAlth AND CHILd CARE HEAdQuARTERS

Ms. Getrude Ncube

Dr. Tsitsi Apollo

Ms. Memory Ndapasowa

POPULATION COUNCIL

Dr. Saiqa Mullick

Ms. Ravikanthi Rapiti

Dr. Samukeliso Dube

Ms. Boitshoko Shoke

\section{WORKSHOP FACILITATORS}

Professor Z. Mike Chirenje - UZ-UCSF

Dr. Nyaradzo M. Mgodi - UZ-UCSF

Dr. Edmore Munongo - ZNFPC

Dr. Joconiah Chirenda - University of Zimbabwe

\section{Ministry of Health AND CHILD CARE -Bulawayo}

PROVINCE

Ms. Bokani F. Maphosa -Bulawayo City

Ms. Dedani Nkala - Ingutsheni Central Hospital

Ms. Pauline S. Makuyana - UBH Hospital

Mr. Sikangezile Moyo - Mpilo Hospital

Ms. Sithabisiwe Nhlabano Ndlovu - Ingutsheni

Central Hospital

\section{CHITUNGWIZA}

Ms. Miriam Kaseke - Chitungwiza Hospital
Ministry of HeALTH AND CHILD CARE -HARARE

Ms. Anna Machiha

Ms. Rosemary Katumba

Ms. Polinah Rwenhamo

Ms. Tanyaradzwa Nyakatawa

Ms. Angeline Matinhure

Ms. Sinokhutemba Xara

HARARE CITY

Ms. Perpetua Kaseke

Ms. Talent Bvochora

Ms. Cathrine Zambe - Harare Hospital

Ministry of HeALTH AND CHILd CARE -MANICALAND PROVINCE

Mr. Charles Uzande

Mr. Denford Kasiyandima

Ms. Jane Roda Mandimutsira

Ms. Jeanette Nyanungo

Ms. Margaret Zvirahwa

Ministry of Health AND CHILd CaRe -MidLANDS

PROVINCE

Ms. Gladys Takawira

Ms. Joan Marembo

Ms. Mercy Mudarikiri

MinistRY OF HEALTH AND CHILD CARE-MASHONALAND EAST

Ms. Inviolata Psiwarayi

Ms. Mercy D. Tugwete

Ms. Enia Mutenga

Ms. Loice Mwedziwendira 
MinistRy OF HEALTH AND CHILD CARE- MASHONALAND CENTRAL

Ms. Emily Tsododo

Ms. Joice Mandire - Bindura Provincial Hospital

Ms. Lilian Ngandu

Ms. Magret Kurehwa

Ministry of Health AND CHILd CaRe- Mashonaland WEST

Mr. Farayi Marufu

Ms. Ratidzo Mugumbate

Ms. Majory Manjoro

Mr. Justice Gonese

Ministry of HeAlth AND ChILD CARE - MASVINGo

PROVINCE

Mr. Clemence Sibanda

Mr. Kasima Nhemachena

Ms. Anna Mashiri

Ministry of Health AND Child CARE - Matebeleland SOUTH PROVINCE

Ms. Beauty J. L. Dube

Ministry of HeAlth AND Child CARE - MATEBeleland NORTH PROVINCE

Mr. Freeman Sibanda

Mr. N. Micheal Mhere

Mr. Pingizile Mpofu

Mr. Todd Ngwenya
MinistRY OF HEALTH AND CHILD CARE - PARTNERS

Ms. Definate Nhamo - AVAC Fellow Pangaea

Ms. Memory Makamba - CeSHHAR ZIM

Mr. Bezel J. Muchovo - LESO

Mr. Kuziwa Elias Garapo - LESO

Mr. Harris Chimuka - MCHIP

Ms. Barbra Engelsman - OPHID

Ms. Megan Dunbar - Pangaea Global AIDS

Ms. Tendayi Westerhof - PAPWC WHHASA

Ms. Emily Gwavava - PSI

Ms. Daisy Nyamukapa - UNFPA

Ms. Anna Mushunje - WASN

Ms. Mary Sandasi WASN -

Ms. Sekai Zungu - WASN

Ms. Annah Rufu - ZACH

Mr. Itayi Viriri - ZAN

Ms. Susan Munangagwa - ZNFPC

Mr. Tonderai Chiduku - ZNNP+

Ms. Sara Page Mtongwiza - OPHID

Ms. Trudence Mangachena - Freelance Journalist

\section{NEDICO}

Ms. Victoria James

Mr. Innocent Yekeye

Ms. Cecilia Musonnza

Ms. Nyaradzo Muchawaya

Mr. Roy Mutandwa 


\section{POPULATION \\ COUNCIL}

Ideas. Evidence. Impact.

\section{APPENDIX 3: Findings from Provider Survey}

We were particularly interested in gathering the attitudes and opinions of provincial-level providers and programme managers on key issues related to potential user groups, possible delivery channels, and overall approach. To complement the rich and robust workshop discussion and thematic breakout groups, we captured quantitatively the answers to several questions through a self-adminsitered closeended questionnaire.

A total of 58 workshop participants completed a self-administered questionnaire. Ten provinces were represented in the repsonses. The largest number of respondents (15) were from Harare province, followed by 8 representing national level sites. Bulawayo and Mashonaland East had 6 representatives each. Other provinces had 2-3 participants, while Matebeleland South province had only one representative. The workshop was successful in attracting service providers as well as programme and facility managers. In fact, almost half (48\%) of respondents identified themselves as programme or facility managers. Workshop participants who completed the survey included: provisional nursing officers, nurse tutors, nurse in charge, national and district medical officers, facility managers, programme managers, advocacy officers, public health officers, STI/HIV focal persons, regional coordinators, research coordinators, civil society representatives, journalists, and interns.

The perspectives of participants are highly instructive, as most of their institutions are already providing prevention methods at their facilities. Here we highlight key themes from the survey.

\section{Prevention Methods Offered}

We queried workshop participants about the types of HIV prevention services they currently provide to their clients. Information provision was cited as the most frequently offered service, with 39 respondents (out of 56) reporting this, followed by condom promotion (38 respondents), and HIV testing and counseling (36). Table 1 shows the type of service and number of respondents who mentioned that their site offers that service.

\section{Table 1: Types of HIV Prevention Methodologies and Tools Offered at Facilities}

\begin{tabular}{lc} 
What HIV prevention methods do you offer at your facility/ies? (N-56) \\
More than one type of service is possible \\
$\begin{array}{l}\text { Information } \\
\text { Condom promotion }\end{array}$ \\
HIV counseling and testing & 38 \\
STI diagnosis/treatment & 36 \\
\hline PMTCT & 34 \\
\hline VMMC & 29 \\
\hline PEP & 25 \\
\hline N/A - Not affiliated with facility & 30 \\
\hline Other & 12 \\
\hline
\end{tabular}




\section{Who Should Benefit from Tenofovir Gel?}

All providers felt the gel would be beneficial to several groups of women, with near universal (98\%) acknowledgement that it would benefit discordant couples. Similarly, $91 \%$ of respondents felt the gel should be made available to married women. Sex workers were viewed as a key group for the gel, with 93\% suggesting that the gel should be made available to them. Women whose partners have multiple partners were also cited by $95 \%$ of respondents as a key group. Importantly, while slightly over half of repsondents mentioned adolescents as a population who should benefit from the gel, many would not actually recoomend it to adolescents.

\section{Table 2: Provider Opinions on Who Should Benefit from Tenofovir Gel}

\begin{tabular}{lcc}
$\begin{array}{l}\text { Who should benefit from tenofovir gel? }(\mathrm{N}=58) \\
\text { Multiple answers were possible }\end{array}$ & \\
& Number & Percent \\
\hline Discordant couples & 57 & 98.3 \\
\hline Women whose partners have multiple partners & 55 & 94.8 \\
\hline Sex workers & 54 & 93.1 \\
\hline Married women & 53 & 91.4 \\
\hline Young women (18-29 yrs) & 52 & 89.7 \\
\hline Women with multiple partners & 52 & 89.7 \\
\hline Women whose partners work away from home & 49 & 84.5 \\
\hline Breastfeeding women & 45 & 77.6 \\
\hline Women who have infrequent, high-risk sex & 44 & 75.9 \\
\hline Pregnant women & 42 & 72.4 \\
\hline Adolescent girls (<18 yrs) & 34 & 58.6
\end{tabular}

\section{Is There Any Group for Whom you Would Not Recommend Tenofovir Gel?}

Nearly half (46.6\%) of respondents reported having at least one group of women for whom they would not recommend tenofovir gel. Several respondents noted that they would not recommend the product to adolescents below age 18 years because it would be viewed as promoting promiscuity. Providing such services to adolescents is subject to both cultural and policy constraints and is viewed as controversial.

While there was a general recognition of the vulnerability of pregnant women, there was concern about the safety of TFV gel both for the women as well as potentially the developing fetus. Some respondents felt that married women may have infrequent but high-risk sex (notably if their husbands have other partners) but that the logistics and timing associated with TFV gel use may be inconvenient. Further, when sexual relations are unplanned or unpredictable, use of coitally dependent products such as TFV gel may pose a challenge. Finally, it was noted that TFV gel would not make sense for HIV-positive women.

\section{Different HIV Prevention Strategies for Different Populatons}

When asked whether there should be different HIV-prevention approaches for different people, responses were mixed. On the one hand, most respondents believe that individuals need to understand HIV- 
prevention options and be able to choose among them based on their own sense of risk and life circumstances. On the other hand, there was recognition that different groups of people may be at higher risk and face particular challenges. Most felt that recommendations should be based on risk and that some groups of people are at higher risk than others (sero-discordant couples, sex workers). Identifying appropriate strategies for high-risk groups will be important in terms of reduction of new cases of HIV. Finally, a combination of prevention strategies will be needed for the effective reduction of HIV transmission in the population.

\section{Service Delivery Settings}

The majority of respondents indicated that there are several opportunities for integrating tenofovir gel into existing service delivery models as indicated in the table below. All 56 respondents suggested that it would be feasible to introduce TFV gel where HCT/VCT services are provided. This was followed by 55 respondents who felt the gel can be introduced within family planning services.

\section{Table 3. Service Delivery Settings Feasible for Providing Tenofovir Gel}

Which service delivery settings do you think would be feasible for providing tenofovir gel? More than one response was possible $(\mathrm{N}=56)$

HCT/VCT services $\quad 56$

Family planning services $\quad 55$

ANC services $\quad 54$

Primary health services $\quad 54$

ARV treatment services $\quad 40$

Sexual assault, rape, violence services 39

Workplace $\quad 35$

Well-baby visits $\quad 35$

VMC services $\quad 34$

Schools 15

Other $\quad 7$


Ideas. Evidence. Impact.

\section{APPENDIX 4: Feedback on Tool - Checklist for Service Delivery}

As an explicit part of the workshop, we sought the input of providers on a Checklist for Service Delivery that was developed by the Population Council as part of the overall microbicide toolkit. (See Appendix 5) The checklist was designed to be used as a guide to help clinics prepare for introduction of microbicides, TFV gel in particular. A total of 46 workshop participants reviewed and commented on the Checklist for Service Delivery.

Overall, most felt that the tool could go a long way in preparing for introduction, and that any introduction effort would need to be well coordinated. Most agreed that there must be a strong commitment to community strengthening and mobilization in order for introduction to be successful. Summary feedback on the checklist is presented below.

The majority (68\%) of respondents considered the checklist to be useful, relevant, appropriate, and comprehensive. Comments included:

- Comprehensive and relevant

- User friendly; most key issues covered

- Will be effective when checking on health facilities

- Very useful and comprehensive

- All necessary pre-introduction checks; checklist is necessary and excellent

- Good because aspects of ethics are covered

- Enough information that will help with quality implementation of tenofovir gel

- Good because it covers important aspects such as: guidelines/protocols, IEC materials, counseling and testing, product use and disposal; includes other preventive strategies

- Several respondents noted the need for improvement. For example, comments included: Appropriate, but this type of data-gathering tool needs to be integrated to existing ones

- Need to select high-impact indicators only and wedge them into existing SRH tools

- Some of the contents are duplicative of SRH checklists

- Unclear as to how often checklist will be used; things may change during the course of roll-out

- Will not work for shops and garages, if they are given the go ahead to distribute 


\section{Top-line Suggestions for Adaptation of Checklist:}

- Will need to be pilot tested; adjustments can be made after piloting the questionnaire

- Programme managers/providers must be trained on how to use the checklist

- Need indicator for provider competency level

- Need to assess staffing levels to see if they are able to cope with additional duties, especially record-keeping and reporting

- Integrated into monitoring and evaluation tools

- Other issues that should be covered:

Demographic data per health facility

- type and level of facility offering the service

- type (cadre) of healthcare provider

Staff training inventory

Pharmacy stores assessment (gel available, minimum/maximum stock calculations)

Staff present, date, visiting team, area of supervision, facility staff sign-off, etc.

Link with other SRH activities (e.g. STI registers, sexual abuse register, youth services, etc.)

Overall, the checklist was viewed positively by the majority of participants and could be pilot tested, adapted and integrated into existing structures and monitoring processes. 


\section{APPENDIX 5: Checklist for Service Delivery}

\section{INTRODUCING TENOFOVIR GEL: A CHECKLIST FOR SERVICE DELIVERY}

This checklist is intended for use by program managers and health providers to determine the readiness of service delivery points to deliver tenofovir gel in a manner that promotes quality interaction between a client and her healthcare provider. The checklist is administered through direct observation by trained observers/researchers and can be used in one of two ways to:

1) identify key areas requiring attention prior to initiating tenofovir gel-related services

2) support the monitoring of related services once tenofovir gel is introduced

The checklist includes the basic elements of high-quality service delivery, and is divided into two sections:

- Section I reviews the clinical elements required for safe and effective delivery of tenofovir gel.

- Section II reviews the program elements required for ensuring that a client makes an informed decision regarding her options for HIV prevention and her use of tenofovir gel if she selects that option.

Disclaimer: The checklist will be updated and revised once service delivery guidelines and protocols for tenofovir gel are developed.

\section{SECTION I: CLINICAL SERVICE DELIVERY}

\begin{tabular}{|c|c|c|}
\hline Element & $\mathrm{Y} / \mathrm{N}$ & Comments \\
\hline $\begin{array}{l}\text { Written medical guidelines, protocols and } \\
\text { standards for ARV-based prevention, including } \\
\text { tenofovir gel, exist and are available at the site }\end{array}$ & & \\
\hline $\begin{array}{l}\text { Providers (by cadre) have been trained in the } \\
\text { provision of tenofovir gel }\end{array}$ & & \\
\hline $\begin{array}{l}\text { Providers have job aids that include information on } \\
\text { and references to tenofovir gel }\end{array}$ & & \\
\hline $\begin{array}{l}\text { Providers have IEC materials to provide } \\
\text { information on tenofivir gel }\end{array}$ & & \\
\hline $\begin{array}{l}\text { Providers assess client eligibility using standard } \\
\text { protocols and forms }\end{array}$ & & \\
\hline $\begin{array}{l}\text { Providers counsel clients about HIV testing and } \\
\text { repeat testing, HIV-prevention options, including } \\
\text { male and female condoms, and provide } \\
\text { instructions on use, side effects, and follow-up } \\
\text { required }\end{array}$ & & \\
\hline
\end{tabular}




\section{SECTION I: CLINICAL SERVICE DELIVERY (continued)}

Providers ask clients about their reproductive intentions and, if desired, counsel and provide a range of contraceptive options on site or by referral

Providers follow protocols for infection prevention and safe disposal of medical waste

Providers give instructions to clients about how to dispose of used applicators and/or other supplies

Client records are accurately and completely maintained and kept confidential

Service statistics are analyzed and reported regularly to supervisory level

A system is in place to periodically assess staff learning and training needs

Facilities and providers receive supportive supervision, including facilitation of problemsolving, performance expectations and feedback, including consequences for poor quality

Facilities have the necessary equipment and supplies to provide tenofovir gel:

- HIV test kits

- Male and female condoms

- Pelvic models (at training facilities)

- Other TBD

The facility has a system to forecast supply requirements for resupply and it is used to submit requests to prevent stock outs

The facility has adequate space and conditions (temperature and humidity control; security) for storing tenofovir gel

Facilities have adequate space to provide privacy for confidential HIV testing and counseling on gel use

Facilities have guidelines on internal and external referrals to ensure comprehensive services are provided and complicated cases are referred for further management 


\section{SECTION II: INFORMED DECISION-MAKING}

\begin{tabular}{|l|l|l|}
\hline Element & Y/N & Comments \\
\hline $\begin{array}{l}\text { A range of HIV prevention options are available to } \\
\text { all groups of clients, including adolescents and } \\
\text { unmarried individuals }\end{array}$ & & \\
\hline $\begin{array}{l}\text { Providers tailor interactions to clients' needs, } \\
\text { circumstances, and concerns }\end{array}$ & & \\
\hline $\begin{array}{l}\text { Providers treat clients with dignity and respect; } \\
\text { they are non-judgmental and sensitive to gender } \\
\text { differences and power imbalances }\end{array}$ & & \\
\hline $\begin{array}{l}\text { Providers use language that clients understand, } \\
\text { assess knowledge gaps, and encourage questions } \\
\text { to check comprehension of information provided }\end{array}$ & & \\
\hline $\begin{array}{l}\text { Providers ensure client privacy and confidentiality, } \\
\text { regardless of the setting }\end{array}$ & & \\
\hline $\begin{array}{l}\text { Facility ensures that linkages exist with other } \\
\text { departments or units within the site to facilitate } \\
\text { integrated services }\end{array}$ & & \\
\hline $\begin{array}{l}\text { Providers ensure that clients understand their } \\
\text { options and how tenofovir gel works, including } \\
\text { risks/benefits, proper use, partial effectiveness, } \\
\text { and potential for resistance }\end{array}$ & & \\
\hline $\begin{array}{l}\text { Providers emphasize the importance of condom } \\
\text { use as the best available means for HIV prevention } \\
\text { and encourage use of male and female condoms } \\
\text { along with tenofovir gel }\end{array}$ & & \\
\hline $\begin{array}{l}\text { Providers provide clear instructions to clients } \\
\text { about follow-up care, possible side effects, where } \\
\text { to go should problems arise, including contact } \\
\text { information and emergency numbers }\end{array}$ & & \\
\hline
\end{tabular}




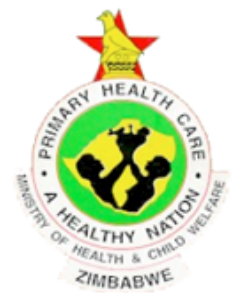

